\title{
Fibrate Antilipidemic Agent
}

National Cancer Institute

\section{Source}

National Cancer Institute. Fibrate Antilipidemic Agent. NCI Thesaurus. Code C98150.

An antilipidemic agent derived from fibric acid that lowers serum LDL cholesterol levels by activating peroxisome proliferator activated receptor alpha (PPARa). 